\title{
A return to normal kidney function in a Caucasian male after COVID-19 induced dialysis-requiring kidney failure
}

Peter Okholm MD ( $\sim$ peterbokholm@gmail.com )

Sygehus Sønderjylland https://orcid.org/0000-0002-0714-5056

Jan Kampmann MD

Sygehus Sønderjylland

\section{Case Report}

Keywords: COVID-19, Hemodialysis, Kidney Failure

Posted Date: July 20th, 2020

DOI: https://doi.org/10.21203/rs.3.rs-44654/v1

License: (c) (1) This work is licensed under a Creative Commons Attribution 4.0 International License.

Read Full License 


\section{Abstract}

Background: Coronavirus disease 2019 also known as COVID-19 has been recognized by WHO as a global pandemic and has spread to most of the world. The disease has a multitude of clinical presentations, and especially the development of acute kidney injury has been associated with increased mortality.

Case Presentation: A 71-year old Caucasian male was admitted with fever and dyspnea to the emergency department. His medical history included type 2 diabetes and hypertension. Blood tests showed a normal kidney function before admission with a creatinine of $0,8 \mathrm{mg} / \mathrm{dL}$. Clinical examination, blood tests and Chest X-ray suggested COVID-19. At admission the diagnose COVID-19 was confirmed, fluid therapy was commenced and Angiotensin-converting enzyme therapy discontinued. The patients was intubated due to respiratory failures and transferred to the intensive care ward where he developed acute anuric kidney failure and was started in continuous renal replacement therapy. After 6 days of dialysis treatment his kidney function slowly started to improve, and he was discharged after 26 days of admission. 42 days after admission his creatinine was measured to $1.3 \mathrm{mg} / \mathrm{dL}$

Conclusion: We present the rare case of a Caucasian male, who not only survived COVID-19 induced kidney failure that required continuous renal replacement therapy, but returned to almost baseline creatinine. We discuss the role of Angiotensin-converting enzyme inhibitor treatment in COVID-19 and the potential pathophysiological mechanism surrounding AKI in COVID-19 patients in literature, and connect it to our case report.

\section{Background}

In December 2019 Wuhan city in the Hubei Province of China became the center of an outbreak of pneumonia of an unknown cause. In January 2020 scientist had identified the cause to be a novel coronavirus, Severe Acute Respiratory Syndrome Coronavirus 2 (SARS-CoV-2). WHO later designated the pneumonia caused by the virus, as coronavirus disease 2019 (COVID-19).

Patients with COVID-19 present with a multitude of clinical presentations. Acute kidney injury and the need for renal replacement therapy has been associated with increased morbidity and mortality. In a retrospective study of COVID-19 patients from Wuhan, all patients $(n=10)$ requiring renal replacement therapy died.

With this case report we present, to our knowledge, the first case of a Caucasian patient tested positive for COVID-19, who, despite developing acute kidney injury and requiring renal replacement therapy, survived and even returned to baseline creatinine.

\section{Case Presentation}


71 year old Caucasian man was admitted to the hospital with fever $\left(>39^{\circ} \mathrm{C}\right)$ and malaise for 10 days. The patient presented with fatigue, malaise and dyspnea. He mentioned having had diarrhea about a week prior to admission.

The patient's medical history included: Type 2 diabetes mellitus and hypertension. Concurrent medications at admission: Metformin (Biguanide) $1 \mathrm{~g} \times 2$ daily, Vildagliptin $50 \mathrm{mg} \times 2$ daily, Ace inhibitor Enalapril $20 \mathrm{mg} \mathrm{x} 1$ and Calcium channel blocker Amlodipine $10 \mathrm{mg} \times 1$ daily).

Exposures: 14 days prior to the admission, the patient had been on a ski trip to Norway. After returning home the patient was informed that one member of the traveling party was tested positive for COVID-19.

On admission, the patient appeared ill but responded relevant to questions. He was awake and alert.

The patient presented with a blood pressure of $149 / 73 \mathrm{mmHg}$, a temperature of $38.9^{\circ} \mathrm{C}$ and a pulse of 106. The peripheral blood oxygen saturation was $84 \%$ without oxygen and $91 \%$ on 5 liters oxygen by nasal cannula. The electrocardiogram was unremarkable, apart from sinus tachycardia.

Auscultation of the lungs revealed decreased breathing sounds, predominantly on the right side, while cardiac auscultation was normal and without murmurs. There was no sign of edema in the lower extremities. Abdominal examination was normal.

Laboratory results at the time of admission can be seen in Table 1:

\begin{tabular}{|c|c|c|}
\hline Table 1 & & \\
\hline Blood test and Units & Patients lab results & Reference value \\
\hline $\mathrm{Hb} \mathrm{g/dL}$ & 13.1 & $12-16$ \\
\hline Leucocytes 10ロ/L & 5,86 & $4-11$ \\
\hline CRP mg/L & 139 & $<10$ \\
\hline Trombocytes $10^{3} / \mathrm{L}$ & 202 & $150-450$ \\
\hline Neutrofilocytes 10ロ/L & 4,97 & $2.0-7.5$ \\
\hline Lymfocytes $10 \square / \mathrm{L}$ & 0,55 & $1.0-4.5$ \\
\hline Monocytes 10ロ/L & 0,29 & $0.3-0.9$ \\
\hline Basofilocytes 10a/L & 0,01 & $0.0-0.30$ \\
\hline Eosinophils 10ロ/L & 0,00 & $0.04-0.4$ \\
\hline Albumine $\mathrm{g} / \mathrm{L}$ & 31 & $35-50$ \\
\hline Potassium $\mathrm{mmol} / \mathrm{L}$ & 4,9 & $3.5-4.6$ \\
\hline Creatinine $\mathrm{mg} / \mathrm{dL}$ & 1.12 & $0.5-1.10$ \\
\hline Blood Urea $\mathrm{g} / \mathrm{dL}$ & 24.92 & $7.0-25$ \\
\hline eGFR & 66 & $>60$ \\
\hline Sodium $\mathrm{mmol} / \mathrm{L}$ & 135 & $135-146$ \\
\hline D-dimer mg/L & 1,34 & 0.7 \\
\hline INR & 0,98 & $0.9-1.2$ \\
\hline ALAT IU/L & 34 & $5-35$ \\
\hline Amylase IU/L & 40 & $25-120$ \\
\hline Billirubine $\mu \mathrm{mol} / \mathrm{L}$ & 6 & $3-17$ \\
\hline Alkaline Phosphatase IU/L & 67 & $30-130$ \\
\hline LDH IU/L & 432 & $140-280$ \\
\hline Blood glucose $\mathrm{mmol} / \mathrm{L}$ & 21,5 & $5,5-10$ \\
\hline
\end{tabular}


The chest $\mathrm{x}$-ray showed ground glass infiltrates characteristic for COVID-19.

Urinary dipstick: +3 glucose,+2 blood +2 protein and negative for Leucocytes, ketones and nitrite.

The patient was given Piperacillin/tazobactam intravenously and given 2 liters of i.v. fluid.

The patient was tested for COVID-19 with oral swap and isolated.

Enalapril, Vildagliptin and Metformin were paused shortly after arrival at the emergency ward.

8 hours after admission the patient's respiration worsened and the patient was sedated, intubated and transferred to the intensive care unit (ICU). During this transfer, the patients test for COVID-19 came back positive.

After admission to the ICU, the patients kidney function slowly deteriorated (Table 2), with diminishing urine production. Furosemide infusion was initiated (increasing to $120 \mathrm{mg} /$ day) and 5 days into the admission, continuous renal replacement therapy was started.

Development of the kidney function and urine output can be seen in Table 2.

\begin{tabular}{|l|l|l|l|l|l|l|l|l|}
\hline Table 2 & & & & & & & & \\
\hline Days since admission & 2 months before & Day 0 & Day 1 & Day 2 & Day 3 & Day 4 & Day 5 & \\
\hline Creat mg/dL & 0.88 & 1.12 & 1.63 & 2.40 & 3.42 & 4.16 & 4.67 & \\
\hline Blood urea g/dL & $\mathrm{x}$ & 24.92 & 28.56 & 33.32 & 40.6 & 53.21 & 62.45 & \\
\hline Urine Output(mL) & $\mathrm{x}$ & $\mathrm{x}$ & $1620 \mathrm{~L}$ & 1410 & 1700 & 800 & 500 & \\
\hline Note: & & & & & & & CRRT Started & \\
\hline
\end{tabular}

\section{Continuous renal replacement therapy (CRRT) specifications:}

Bloodflow: $130 \mathrm{ml} / \mathrm{min}$, PBP flow with Regiocit: $1300 \mathrm{ml} / \mathrm{h}$

Dialysate with Biphozyl: $1300 \mathrm{ml} / \mathrm{h}$

Postreplacement fluid with Phoxilium: $400 \mathrm{ml} / \mathrm{h}$

Fluid removal 100-200 $\mathrm{ml} /$ hour

Filter: ST150 Prismaflex

The Patient had no urine production on day 6 , and was kept in a negative fluid balance the next couple of days.

On Day 9 the patient had increasing diuresis and the CRRT fluid removal was stopped and the patient was extubated. The patient's clinical status slowly improved and on day 11, the CRRT was paused (6 days CRRT in total), and the patient was given Zaroxylin $5 \mathrm{mg} \times 2$ and continuous furosemide infusion 40 $\mathrm{mg} /$ hour. Slowly but steadily the patient's kidney function and urine production improved.

On day 14 he was discharged from the ICU with a urine production of $3000 \mathrm{~mL} /$ day. The renal function improved gradually and 26 days after the admission, the patient was discharged to primary care with a 
creatinine of $1.9 \mathrm{mg} / \mathrm{dL}$. 42 days after admission, the patient's creatinine was $1.3 \mathrm{mg} / \mathrm{dL}$

\section{Discussion}

\section{Cause of acute kidney injury in COVID-19}

The prevalence of acute kidney injury (AKI) in Covid-19 varies from $0.5 \%$ (1) of patients to $5 \%$ (2) according to Chinese studies. Cheng et al. reported that $43.9 \%$ of patients with covid- 19 had proteinuria and $26.7 \%$ had hematuria on admission (2). AKI was associated with increased morbidity and mortality (2). Zhou et al reported that all of the patients with COVID-19 requiring renal replacement therapy died during their study period (3).

A Chinese study performed postmortem renal biopsies on 6 patients. Severe acute tubular injury, prominent lymphocyte infiltration, detection of viral antigen in tubular epithelial cells, macrophage infiltration and complement C5b-9 deposition were seen (B. Diao, C.H. Wang, R.S. Wang, Z.Q. Feng, Y.J. Tan, H.M. Wang, et al:: Human kidney is a target for novel severe acute respiratory syndrome coronavirus 2 [SARS-CoV-2] infection [preprint posted online April 10, 2020]. medRxiv doi:10.1101/2020.03.04.20031120). A study investigating 26 postmortem renal biopsies in COVID-19 patients showed also acute proximal tubular injury, but, additionally, peritubular erythrocyte aggregation and glomerular fibrin thrombi with ischemic collapse and signs of pigment casts from rhabdomyolysis (4). To our knowledge, the only alive kidney biopsy performed in Covid-19 patients with AKI was an African American woman with collapsing glomerulonephritis (5).

Ronco et al proposed the following three potential pathways of kidney damage in COVID-19 (6):

1) Cytokine damage or cytokine release syndrome which leads to intra-renal inflammation. Increased vascular permeability, volume depletion and cardiomyopathy leading to cardio-renal syndrome. Cardiorenal syndrome can generally be defined as a pathophysiological disorder of the heart and kidneys, in which dysfunction of one organ may induce dysfunction in the other (7). In the following cases, various cardiac dysfunction lead to compromised circulation and, as a result, to acute kidney injury.

2) Organ crosstalk where high peak airway pressure and intra-abdominal hypertension causes renal compartment syndrome. Alveolar damage leads to renal medullary hypoxia. Cardiomyopathy and myocarditis lead to impaired circulation causing cardio-renal syndrome.

3) Systemic effects: positive fluid balance leading to renal compartment syndrome, third space loss leading to renal hypo-perfusion and endotoxins leading to septic AKI.

Rhabdomyolysis has been described as a feature in both organ crosstalk and systemic effects. CRRT has been suggested as a causal treatment to remove cytokines and treat rhabdomyolysis (6).

Batlle et al agree that AKI in COVID-19 patients appears to involve a complex process driven by virusmediated injury and cytokine storm. However, the authors additionally propose that angiotensin II 
pathway activation, dysregulation of complement, hyper-coagulation, and micro-angiopathy play a role (8).

Angiotensin converting enzyme (ACE2) is expressed, among others, in brush border apical membrane of the proximal tubule and podocytes (9). SARS-CoV-2, the strain of coronavirus that causes COVID-19, can bind to renal epithelial cells and injure them. Furthermore, an association between angiotensin II and overactivity of immune and complement pathways and the coagulation systems, have been proposed to play a role in AKI in Covid-19 patients (8).

Elevated d-dimer levels have been shown to correlate with worse outcome pointing towards a hypercoagulable state in COVID-19 patients which potentially could lead to cortical necrosis $(8,10)$.

Our patient presented with a d-dimer of 1.34 and only microscopic hematuria. Since cortical necrosis is causing irreversible damage (8), we suppose that, if at all, our patient only suffered from mild cortical necrosis.

Concerns have been raised regarding the safety of inhibitors of the renin-angiotensin-aldosterone system (RAAS) in COVID-19 patients. Recommendations from some medical societies suggest that RAAS inhibitors should be continued since the available data points to the benefits outweighing the risks (11). However NICE guidelines from the $21^{\text {st }}$ of May state that at this stage no conclusion on the role of ACE inhibitors in COVID-19 can be drawn due to the poor quality and subject to bias and confounding of the available data (12). Although mainly based on opinions and observational data, withdrawal or reduction of RAAS inhibition is part of many guidelines for AKI to improve renal perfusion (13). At least in our case report, the cessation of ACE inhibitor had a favorable effect.

We have presented a rare case of full renal recovery after acute, anuric renal failure due to COVID-19. The weakness of the present report is the lack of a renal biopsy, creatinine kinase/myoglobin or reliable quantification of proteinuria. Since the patient was receiving critical care and was later quickly regaining his renal function, a renal biopsy was considered unnecessary in terms of treatment regimen at the time. Our patient was Caucasian and his renal function improved quickly. We, therefore, do not assume collapsing glomerulonephritis as cause for the patient's AKI. We argue that the most plausible cause was acute tubular injury. We cannot rule out rhabdomyolysis as a contributing factor. However, since urine color was described as normal and electrolytes were unaffected, we consider rhabdomyolysis unlikely.

\section{Conclusion}

In conclusion, this is the first case report on a COVID-19 patient with AKI receiving acute renal replacement therapy not only surviving, but also, returning to baseline creatinine 42 days after admission. The patient's ACE inhibitor was discontinued and he was treated with CRRT. These factors may have played a role in the restitution of renal function and survival in AKI patients and warrant further investigation. 


\section{Declarations}

\section{Ethics approval and consent to participate}

Not Applicable

\section{Patient perspective}

During his discharge, the patient was thankful and felt he had received proper care.

\section{Consent for publication}

The patient has given written consent to publish his medical data for this article.

\section{Availability of data and materials}

Data sharing not applicable to this article, because no datasets were generated or analyzed during the current study.

\section{Competing interests}

The authors declare that they have no competing interests

\section{Funding}

The authors received no funding

\section{Authors' contributions}

PO wrote the introduction, case presentation and contributed to the discussion and conclusion.

JK's main contribution was in the discussion and conclusion segments.

\section{Acknowledgements}

Eithne Hayes Bauer - proof reading Journal.

Line Aas Mortensen - initiator who suggested to write a case report and proof reader

\section{References}

1. Guan WJ, Ni ZY, Hu Y, Liang WH, Ou CQ, He JX, et al. Clinical Characteristics of Coronavirus Disease 2019 in China. N Engl J Med. 2020;382(18):1708-20.

2. Cheng $Y$, Luo R, Wang $K$, Zhang $M$, Wang $Z$, Dong $L$, et al. Kidney disease is associated with inhospital death of patients with COVID-19. Kidney Int. 2020;97(5):829-38. 
3. Zhou F, Yu T, Du R, Fan G, Liu Y, Liu Z, et al. Clinical course and risk factors for mortality of adult inpatients with COVID-19 in Wuhan, China: a retrospective cohort study. Lancet. 2020;395(10229):1054-62.

4. Su H, Yang M, Wan C, Yi LX, Tang F, Zhu HY, et al. Renal histopathological analysis of 26 postmortem findings of patients with COVID-19 in China. Kidney Int. 2020.

5. Larsen CP, Bourne TD, Wilson JD, Saqqa O, Sharshir MA. Collapsing Glomerulopathy in a Patient With Coronavirus Disease 2019 (COVID-19). Kidney Int Rep. 2020.

6. Ronco C, Reis T. Kidney involvement in COVID-19 and rationale for extracorporeal therapies. Nat Rev Nephrol. 2020.

7. Ronco C, Bellasi A, Di Lullo L. Cardiorenal Syndrome: An Overview. Adv Chronic Kidney Dis. 2018;25(5):382-90.

8. Batlle D, Soler MJ, Sparks MA, Hiremath S, South AM, Welling PA, et al. Acute Kidney Injury in COVID19: Emerging Evidence of a Distinct Pathophysiology. J Am Soc Nephrol. 2020.

9. Ye M, Wysocki J, William J, Soler MJ, Cokic I, Batlle D. Glomerular localization and expression of Angiotensin-converting enzyme 2 and Angiotensin-converting enzyme: implications for albuminuria in diabetes. J Am Soc Nephrol. 2006;17(11):3067-75.

10. Tang N, Li D, Wang X, Sun Z. Abnormal coagulation parameters are associated with poor prognosis in patients with novel coronavirus pneumonia. J Thromb Haemost. 2020;18(4):844-7.

11. Rabb H. Kidney diseases in the time of COVID-19: major challenges to patient care. J Clin Invest. 2020.

12. NICE. COVID-19 rapid evidence summary: angiotensin-converting enzyme inhibitors (ACEls) or angiotensin receptor blockers (ARBs) in people with or at risk of COVID-19).

13. Tomson C, Tomlinson LA. Stopping RAS Inhibitors to Minimize AKI: More Harm than Good? Clin J Am Soc Nephrol. 2019;14(4):617-9. 